\title{
Underground Parking Intelligent Monitoring System Based on Internet of Things
}

\author{
Hongyan Zhang ${ }^{1, *}$, Qinghong Liu ${ }^{1}$, and Omar Masud ${ }^{2}$ \\ ${ }^{I}$ Jilin Province Economic Management Cadre College, Changchun 130012, China \\ ${ }^{2}$ Computer Science Department, Taif University, KSA
}

\begin{abstract}
China's economic development led directly drive the progress of science and technology, and now the high-tech fields penetrate gradually into various charges. Now the parking fee system is changing the direction of intelligent systems. Advanced and reliable system is more advantages parking fees, and the role of management systems is growing. Social development also affects the use of increasingly high cost of land, parking gradually transformed into an underground car park, so you can save land resources and construction costs. Intelligent monitoring system underground parking based networking technology is a fast and efficient, fair and accurate, parking management measures science economy, achieving a combination of static and dynamic vehicle management. From the user's perspective, its service is efficient, fee transparency, accuracy. Analysis from the perspective of the manager, the late intelligent system is easy to operate and maintain, high degree of automation, to a large extent reduce the workload of managers. From the investor perspective, the construction of underground parking reduced investment costs, basically avoid mistakes and any form of cheating, prevent the loss of parking fee, so that the return investors a reliable guarantee. Analysis of the current draw on the advantages and disadvantages parking system, the introduction of internet of things technology to further build underground parking system. From the user's point of view, to provide the best path for every user needs to stop, save time and improve efficiency in the use of parking spaces. Achieve customer satisfaction and convenience managers manage scheduling.
\end{abstract}

Keywords: Internet of things, underground parking, parking guidance, path optimization, wireless network.

\section{INTRODUCTION}

With the development of the era China's economy is developing rapidly, people's living standards gradually improved, and now the car has become the people's daily lives main travel tool. With the increasing of the vehicle, to a certain extent also bring some negative impact to the community. Vehicle exhaust concentration within the underground car park is relatively large, long stay in the environment would have been affected body. In addition, owners often go out because of fast enough to find a parking space. In some large underground parking area, although there are many parking spaces, but the owners cannot find exactly empty spaces in the shortest time or back to get the vehicles do not know where car and so on. There are problems, then there also are countermeasures. With the development of technology, people began to pursue intelligent lifestyle concept, internet of things began coming into sight. In order to establish a sound system of underground parking, we use internet of things technology in the existing parking system to provide more detailed information to the owners: parking location, charge mode, the remaining number of parking spaces, driving path. Try to save the owner time to find parking space, reduce traffic pressure.

\section{BASIC STATUS AND SIGNIFICANCE OF PARK- ING SYSTEM}

Based on China's large population can use less land resources. With the construction of modern buildings, parking lots and more changes to the underground car park, so can save land resources and increase the number of parking spaces. But now most of the parking spaces available to the user only the remaining amount of information in a car park, which does not provide a specific location. Even if just an arbitrary assignment to provide parking spaces and will not choose the best parking spaces from the user's perspective. But the construction of underground parking special geographical considerations, to fully consider the ventilation, drainage, lighting, fire, mold and other factors. In particular, careful consideration ventilation, because high concentrations of exhaust unlike open-air parking lot due to a large number of vehicles produced will soon gather dissipate not affect people's health. But the underground car park ventilation effect is not very satisfactory, so a lot of automobile exhaust may accumulate, especially have great influence on children. Therefore, guiding strategy unreasonable underground parking can easily lead to confusion parking internal order to the user, causing more bad influence, but also allows users to stay in the ground too long, excessive inhalation of harmful gases. So the introduction of advanced internet of things technology build intelligent monitoring system to create better services and working environment for the user and the administrator. 
Based on currently available parking system studied in combination with the special circumstances the parking lot, think that to achieve effective parking guidance needs to provide users with real-time and accurate information to the user to recommend the best parking location and parking path.

Internet of things technology into an underground parking system can effectively solve some of the problems of traditional parking systems. For example, the use of the sense coil to obtain the information which led to the accumulation of data collection system paralyzed. Information between different parking system is not shared, not the most good parking guide paths and other issues. Wireless geomagnetic detection vehicles, ultrasonic parking spaces, and the results not only are higher detection accuracy and installation is relatively easy. Parking guidance achieve a unified command platform, and dynamic traffic information on the internet data sharing, enabling parking queries and electronic payment functions, and ultimately build to meet the needs of users underground parking intelligent monitoring systems.

\section{INTERNET OF THINGS SYSTEM AND TECH- NICAL OVERVIEW}

Internet of things system mainly consists of three parts: perception control layer, the use of RFID, two-dimensional code, sensors perceive the object recognition. Network transport layer, the data layer from the perception identification information via the Internet, TV network, and mobile communication networks and other infrastructure bearer network to the application service layer. Application service layer, using cloud computing, data mining and other intelligent computing technology to complete the object of intelligent control and management, and apply it to specific areas of the industry. Information exchange, the command transmission and architecture of the internet of things between the three parts.

Perception layer is mainly to identify objects and collect information from related objects, and the information processing to reduce data redundancy. Internet of things transport layer is the nerve center of the system, the information obtained by the perception layer send to the application layer to be processed applications. Application layer will eventually service to users, simple operation, enabling intelligent life.

Internet of things technology is a network composed of a variety of techniques, many areas involved. Internet of things technology has the advantage of making its application field quite broad. In terms of the transport sector, the sensors, data analysis and processing, global positioning systems and other internet of things technology used in modern traffic, enabling intelligent traffic environment. The main technical networking technology involved in Table $\mathbf{1}$ below.

Achieve automatic parking spaces in the underground car park guidance system is an application of networking technology. Sensor devices installed at each parking space parking lot on parking spaces for real-time collection are occupied by other information, and will be collected through the network data information to the data processing center. The information collection processing and analysis calculate the optimal route parking and parking optimal feedback to the user.

\section{INTERNET OF THINGS UNDERGROUND PARK- ING SYSTEM DESIGN AND ANALYSIS}

If you want to provide users with the best service, you first need to consider the following aspects:

1. The use of the basic characteristics and requirements of groups.

2. Analysis functions of the system clear system.

3. Parking location and its own special circumstances, the design of the system so as to better serve the masses. Underground parking monitoring system mainly includes: parking user, parking management, regional guidance centers, video surveillance systems, indoor air quality monitoring, instrument light, drainage systems. The main part of the program segments as shown in Table 2.

Through a comprehensive analysis of underground parking system and user needs, underground parking monitoring system based on internet of things technology should have the following features:

(1) Acquisition and display name parking, area, location, traffic conditions near fees and billing methods, the surrounding traffic and other data transfer methods.

(2) Parking managers need to understand the use of parking spaces per vehicle entry / open a case, enter basic information about vehicle parking, parking reservation information, traffic information. Underground car parks is major convenience managers parking lot to maintain order and ensure safety of vehicle parking, a timely change and adjust management strategies, improve operational efficiency.

(3) Every car parking shall have a uniform means of identification (eg RFID tags), the owner of the information is correct parking of vehicles, vehicle information, parking information logo.

(4) A variety of information gathering nodes with data collection and transmission capabilities to facilitate installation and post-inspection, maintenance, data to be able to achieve rapid and effective treatment to ensure reliable access to information.

(5) To have a full range of monitoring systems, as well as real-time monitoring of environmental quality in a car park, and the parking lot to the user managers to provide better service and work environment.

(6) To finally achieve cars and cars, people and cars, people and people contacted, user-friendly parking and pick up the car, easy to manage scheduling managers to create better indoor parking traffic order, to ensure safety.

When designing the system to consider the practicality, fully meet user requirements for underground parking system, consider the convenience of each part of the data acquisition and processing. Make the user's needs first, and to 
Table 1. Internet of things key technologies.

\begin{tabular}{|c|c|}
\hline Perception Layer & Rf technology, zigbee technology, positioning technology, sensors, two-dimensional code technology \\
\hline \hline Transport layer & Transport layer, wsn technology, mobile communication technology \\
\hline Application layer & Artificial intelligence, middleware, M2M technology, data mining \\
\hline
\end{tabular}

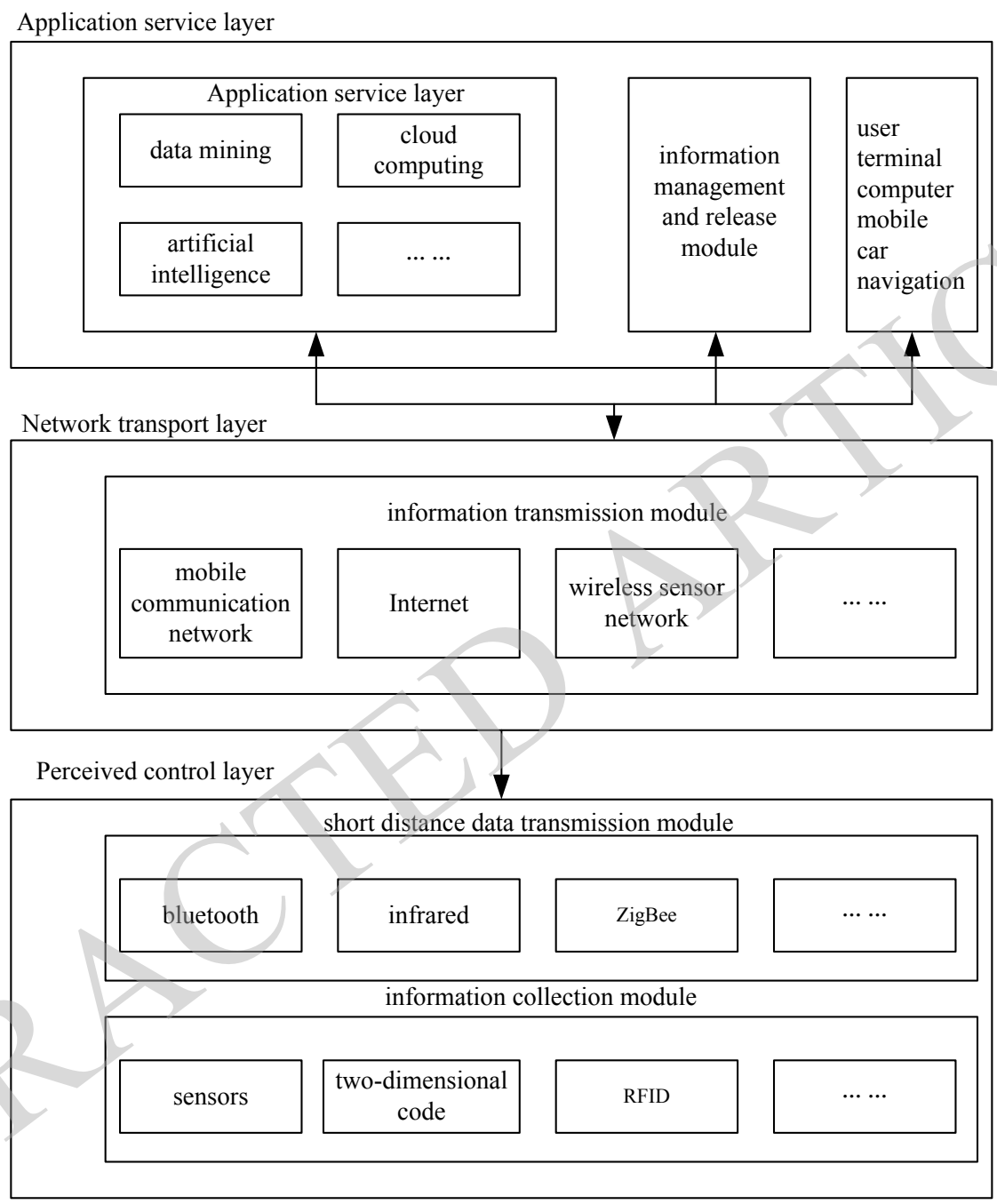

Fig. (1). The framework of Basement Parking Intelligent Monitoring System based on the internet of things.

design user-friendly interactive interface, easy operation and simple implementation. With the use of networking technology system should be scalable, longer service life, stable and so on. When designing the system to fully consider the cost of implementing the time, while fully meet user demand to reduce as much as possible on the basis of funds, but also consider the future maintenance of the system convenient cost and other issues. Different from the outdoor parking, underground parking to take into account the lighting problem, it is necessary to ensure adequate lighting conditions also possible to save energy. In almost closed space will be poor people's sense of direction and even some users almost nothing, so the need to set a reasonable accurate indoororiented tips, to provide users with better service. The collected data will be centralized in the data monitoring center, so to ensure the security of user information does not leak. Underground parking design will also be required to monitor the content of indoor air content of harmful gases whether is exceeded, the drainage system is in normal operating status.

According to the meaning of internet of things seen "material objects" connected, so included underground parking system in every car should have an ID number be identified, it will be the key to the formation of the foundation and intelligent networking systems. Parking guidance system based on user needs, operational requirements and combine the key technologies of things, will be designed as shown in Fig. (1) underground parking intelligent monitoring system based on the framework of internet of things. 
Table 2. Underground parking intelligent monitoring system user needs analysis.

\begin{tabular}{|c|c|}
\hline Users and service providers & Environmental monitoring \\
\hline \hline Parking user & $\begin{array}{r}\text { The parking lot of free parking spaces, the area where the vacancy, the optimal travel route and other real-time } \\
\text { information and the ability to realize the electronic payment }\end{array}$ \\
\hline Parking management & $\begin{array}{r}\text { Enter the parking of vehicle information (license plate, color, etc.), vehicles entering and out of time and path in- } \\
\text { formation vacant parking spaces, parking spaces usage and reservation information, etc. }\end{array}$ \\
\hline Regional monitoring centre & $\begin{array}{r}\text { Each vacant parking management within the range parking information, into the parking vehicle information (li- } \\
\text { cense plate, color, etc.), current road traffic conditions, etc. }\end{array}$ \\
\hline Environmental monitoring & In the parking lot of harmful gas content, temperature, lighting and humidity \\
\hline
\end{tabular}

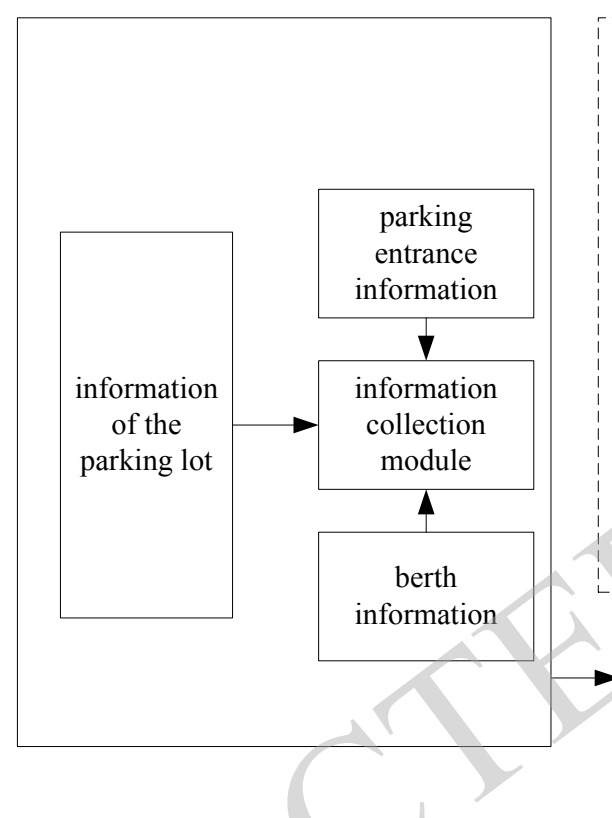

Fig. (2). The diagram of System module.

The ultimate goal of parking intelligent monitoring system is to provide parking information and storage data into the monitoring center, and ultimately to the user and parking management. The system needs to have the number of information processing and memory functions, because the system requires accurate real-time parking information collection vehicle, and then sent to the parking users. However, the collected information cannot be immediately used as the basis for guiding the vehicle stopping, so the system must have a data processing and storage capabilities, analysis of the data after the processing into useful information to the user. Acquisition and sending information transmission channels are required, so the system must also have transfer functions. If the underground parking system considered parking in advance reservation function, the relationship between the various modules of the system shown in Fig. (2).

The information collection function of the system is in the lowermost layer, which is at the origin of all data. It collects and storage the data for a short period of time. Through the RF identification technology, parking sensor, video monitoring equipment for the basic characteristics of the vehicle information, such as whether the parking free information, etc. The collected data is sent to the network via the WSN transport layer, then data is processed and analyzed. Based on data collection module of internet of things need to have real-time accurate sailed out into the parking lot of vehicles and the use of the parking spaces, parking lot at the entrance of the traffic conditions.

Information transmission function must be able to ensure timely and accurately transfer the data collected in order to achieve the interaction between the collection and processing of information, interactive data processing results between users. Currently, the data transmission technology includes wired transmission and wireless transmission. The user can select the transmission mode according to the actual situation (geographical environment, transmission distance, construction costs and other factors). As we all know, the distance between the parking spaces in the car park is relatively short, in order to eventually achieve cars and cars, people and people accurate transmission of information, these can use WSN technology. Because WSN technology can process large amounts of information, and the ability to install a large 


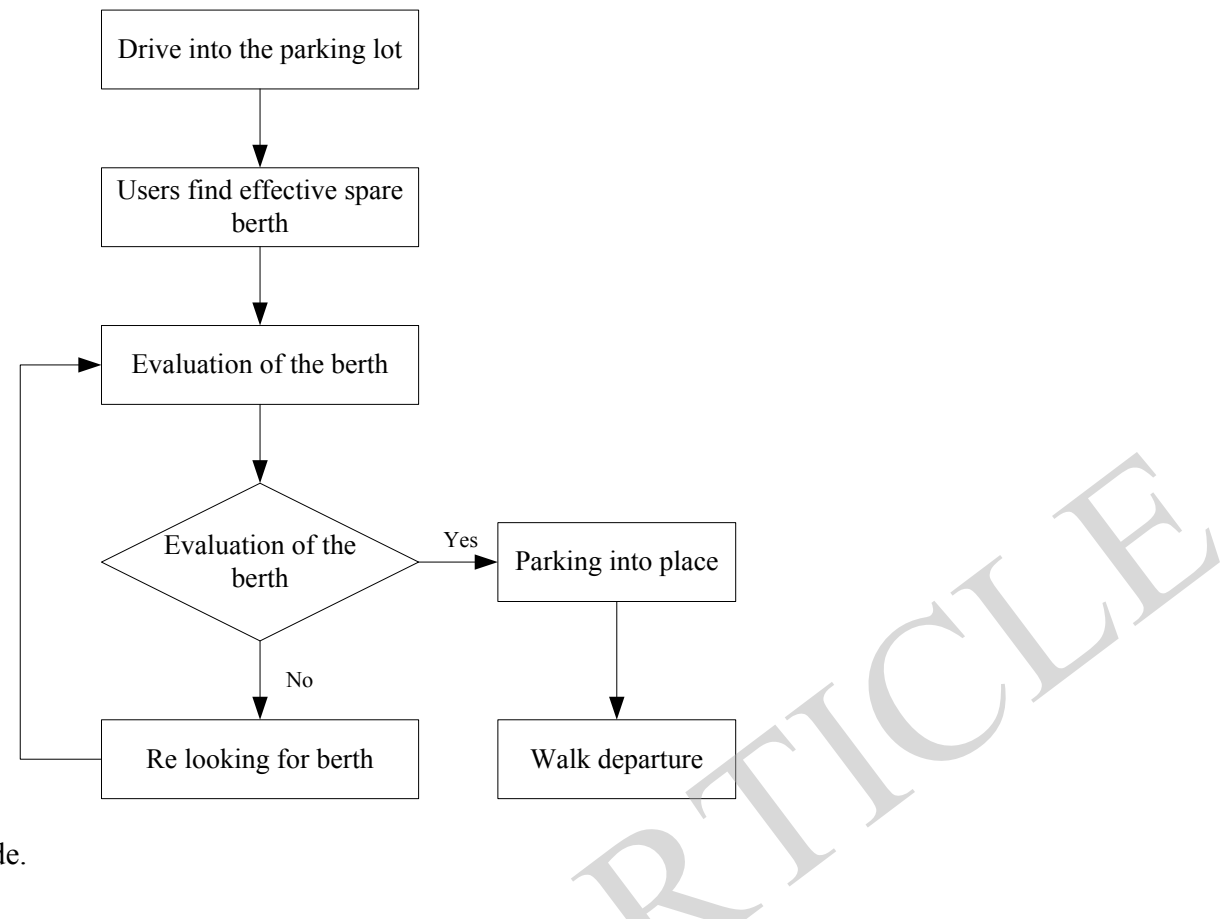

Fig. (3). Parking flowchart artificial guide.

number of sensor nodes in a fault-tolerant system would enhance the coverage more extensive, to improve the monitoring capacity of the system to a large extent.

Information analysis and processing function makes the collected information converted into voice or image or text form, then sent to the user to achieve the ultimate goal of intelligent monitoring. Many types of objects in the system of internet of things, information transmission "substance and substance" between the need to be pre-pretreatment, so the data need to deal with a lot of this module, a very large amount of computation. To build only the data processing system must first solve the problem of the system. Underground parking system based on internet of things needs the support of cloud computing technology, analytical instruments as limited internet terminal, computing storage capacity is limited, long-term use will cause inconvenience to the entire system.

Information management is the ultimate goal of sending the whole system, which is directly in contact with the user, fully embodies the concept of intelligence. One of the main purpose of the intelligent monitoring system to pass information to the user, but sending information quickly and accurately is critical to the user. Sending data management has two main functions. One is basic information about parking vehicle information, parking usage data such as information, or by a variety of forms such as hand-held or vehiclemounted terminals to send one classification to store and manage data center sent dynamic information. If after the establishment of the collected data to the database for classification processing, the data of different users according to their needs, while enabling a plurality of users to share data, information exchange can be achieved between users. Parking information release system primarily for users and parking managers. Users need to know the parking lot of information, the number of free parking spaces and parking information. While managers need to know that information in addition to outside monitoring system also needs to know whether the car park in normal working condition, the air quality standards, such as whether the car park.

Underground parking is almost 24 hours a day of continuous work, so the requirements for system center server is relatively high. It should be able to ensure that the system is stable and reliable working condition. In addition, the system service centers also need to be able to support a variety of interfaces and operating software. System at work will inevitably fail, and underground parking area is quite large. So the electricity use will increase, if they lose the power of the whole system work will be a problem. It is necessary to make the whole system equipment sub-regional use the power, but also fully consider the contingency arrangements to work with regular checks. In addition, data collection needs a stable transmission of data, but also needs to consider the humidity of the underground car park, the temperature, the content of harmful gases in the air exceeded, the health situation, anti-jamming capability. Especially for relatively speaking, underground parking and enclosed it needs to do the work of ventilation to avoid excessive lead content in ground vehicles gathered excessive harmful gases, causing bad impact on users. Underground parking geographical location is relatively low, so if the drainage system is not good enough to do, encounter a rainy day can cause a lot of water, it will cause some problems with the loss to the user.

The entire system software services are used more for parking. Whether for a parking space to spare us through the ground sensors will collect the information transmitted by WSN. For vehicles to locate in the parking lot, parking lot 


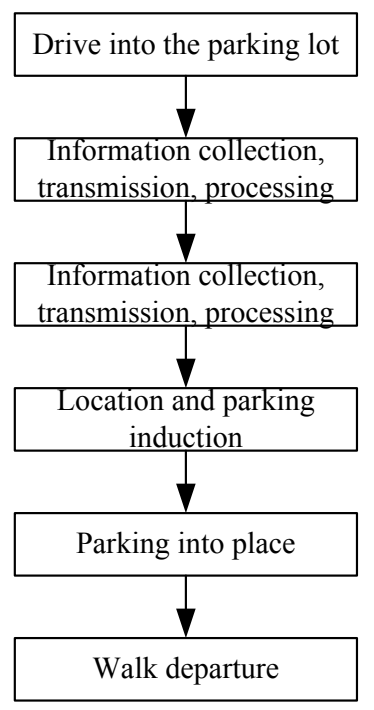

Fig. (4). Parking guidance system flow.

need to be keyed, need to determine whether the data correctly, and other functions. If it create a shared database, we also need to choose based on the needs of Access, MS SQ Server and so on. The whole system needs to have the support computer operating systems, application software systems.

Parking in the car park is usually carried out by the parking management or personnel to guide the user to search for vacant spaces into the parking lot. Stopping flow is as shown below, so that not only can save time and can not reflect the effect of intelligent applications. The use of advanced networking technologies, through analysis of the data processing provides the best path for the user location and parking, parking flow as shown in Figs. (3) and (4).

By contrast to the traditional parking system, it is easy to draw, with intelligent monitoring boot system process will not only be able to avoid parking spaces blindly looking enough to save users time, but also to improve the efficiency of the parking lot full, reduce parking workload management personnel.

Intelligent parking system with the user's personal information (advance are stored in onboard electronic tags) and the parking lot inside information currently in the intelligent monitoring system based on internet of things technology provides the optimal path for users. First, the user selects the parking space clearly affect the main factors in determining and indicating. Secondly, the use of data analysis collector car park spaces in the parking lot to choose from, to determine the effective parking. Then, using the traffic information intelligent monitoring system based on internet of things provide parking within the analysis results effective decision-making value size of parking spaces. Next, according to the optimal path algorithm used by the system to elect the best travel routes and parking spaces, and parking lights inside through voice prompts and tips to guide vehicles.

After selecting a valid parking space, the use of efficient and accurate algorithms and systems based on vehicle information collected within the parking lot on the road, be calcu- lated quickly reach every car on the road in the shortest path designated parking spaces, and after the user to walk the shortest distance exports.

\section{CONCLUSION}

Underground parking system is an effective way to solve parking problems. But now each car parking system is not uniform, it is more difficult to form a unified system of institutions, inconvenient for parking users. Underground parking drawback own narrow line of sight, is not conducive to the user in a specific time period and timely discovery of free parking spaces. It not only allows users to spend more time looking for a parking space, but also there are not very satisfied with the need to re-find spare parking spaces. Parking people wasted a lot of time, but also makes efficient use of the car park will be reduced. Through the analysis of existing systems and combine the underground car park of the environment, in the existing parking system introduced on the basis of our networking technology, timeliness and accuracy of data collection as much as possible, to provide users with the best parking path and parking locations. Disposable achieve user satisfaction parking spaces, and further improve the efficient use of parking spaces.

In order to achieve intelligent underground parking system, the introduction of networking technology in this study, although part of the existing system can solve the problems. But due to limited knowledge and experience to consider the issue is not comprehensive enough, there are still many areas for improvement:

(1) This study is just in theory to analyze the underground parking system, so the case will differ from the actual application in practice will have more problems, the need to further improve and perfect follow-up.

(2) Because there is no fully effective actual data, so choose the best parking spaces, there is no data on the dynamics of the vehicle mark, the need to further explore in future work. 


\section{CONFLICT OF INTEREST}

The author confirms that this article content has no conflict of interest.

\section{ACKNOWLEDGEMENTS}

Declared none.

\section{REFERENCES}

[1] P. Yu, "Residential intelligent parking management system solutions", Security Technology, vol. 2, no. 3, pp. 48-49, 2003.

[2] H. Z. Guan and L. H. Liu, "Planning and design study parking guidance system", Highway and Transportation Research, vol. 20, no. 1 , pp. 136-139, 2003.
[3] Y. W. Deng, Intelligent parking management system. Changsha: Hunan University, 2006.

[4] S. Sardar and Y. H. Lee, "A Quantitative Model of Supply Chain Innovativeness as a Disruption Management Strategy in the Textile Industry", Advances in Industrial Engineering and Management, vol. 4, no. 1, pp. 9-28, 2015.

[5] L. Tang, Development status of the networking industry and industry chain analysis. Beijing: Beijing University of Posts and Telecommunications, 2010.

[6] Z. L. Liu, "Review on Regional and spatial-economic impact from high speed Rails", African journal of Business Management, vol. 6 , no. 35, pp. 9738-9741, 2012

[7] M. Z. Guang, C. X. Zheng, and W. Jiang, "Forecast analysis of talent needs based on gray theory shipbuilding skills", Vocational and Technical Education, no. 5, pp. 5-8, 2014.

Received: September 16, 2014

(C) Zhang et al.; Licensee Bentham Open.

This is an open access article licensed under the terms of the Creative Commons Attribution Non-Commercial License (http://creativecommons.org/licenses/by-nc/3.0/) which permits unrestricted, non-commercial use, distribution and reproduction in any medium, provided the work is properly cited. 